\title{
СРАВНИТЕЛЬНЫЙ АНАЛИЗ ВЛИЯНИЯ ВИТАМИНА С И ОРОТАТА КАЛИЯ НА МОРФОЛОГИЧЕСКУЮ КАРТИНУ ПРИ ИМПЛАНТАЦИИ ГЕРНИОИМПЛАНТАТА В ЭКСПЕРИМЕНТЕ
}

\author{
( Лазаренко В.А., Иванов С.В., Иванов И.С., Иванов А.В., Цуканов А.В., \\ Тарабрин Д.В., Кулабухов А.С., Тарабрина О.В.
}

\author{
Курский государственный медицинский университет (КГМУ) \\ Россия, 305041, Курская область, г. Курск, ул. К. Маркса, д. 3
}

\begin{abstract}
Цель работы - сравнительное экспериментальное изучение влияния препаратов витамина С и оротата калия на процесс формирования соединительнотканной капсулы вокруг сетчатого имплантата.

Материалы и методы. Эксперимент был выполнен на 150 белых мышах. I группа животных после операции получала стандартный пищевой рацион. II и III группе животных к стандартному пищевому рациону добавляли витамин С и оротат калия соответственно. От животных получали гистологические срезы и помещали на предметные стекла, окрашивали гематоксилином и эозином. Затем проводили морфометрию в капсуле вокруг нитей имплантата.

Результаты. Сравнение клеточного состава регенерирующей вокруг герниоимплантата соединительной ткани в исследуемых группах животных показало, что в обеих экспериментальных группах уже на 7-е сутки после имплантации имплантата клетки фибробластического ряда количественно преобладают над клеткаминерезидентами. В раннем послеоперационном периоде (7-30 сутки) введение в пищевой рацион животных витамина С способствует более быстрому увеличению популяции фибробластов. Аналогичный эффект оротата калия реализуется позже, уже на стадии моделирования и ремоделирования капсулы вокруг нитей имплантата, на сроках 60 и 90 суток после экспериментального оперативного вмешательства.

Заключение. В эксперименте определен эффект препаратов в зоне имплантации герниоимплантата, который проявлялся достоверно более выраженной пролиферацией клеток фибробластического ряда.

Ключевые слова: вентральная грыжа; коллаген; морфометрия.

Лазаренко Виктор Анатольевич - д-р. мед. наук, профессор, ректор, зав. кафедрой хирургических болезней ФПО, КГмУ, г. Курск. ORCID iD: 0000-0002-2069-7701. E-mail: azaroks@mail.ru

Иванов Сергей Викторович - д-р. мед. наук, профессор, зав. кафедрой хирургических болезней № 1, КГМУ, г. Курск. ORCID iD: 0000-0001-7540-5748. E-mail: gospithirivanov@yandex.ru

Иванов Илья Сергеевич - д-р. мед. наук, профессор кафедры хирургических болезней № 1, KГMУ, г. Kypск. ORCID iD: 0000-0003-4408-961X. E-mail: ivanov.is@mail.ru

Иванов Александр Викторович - д-р. мед. наук, профессор, зав. кафедрой гистологии, эмбриологии, цитологии, КГмУ, г. Курск. ORCID iD: 0000-0002-2412-0475. E-mail: anatomy@mail.ru

Цуканов Андрей Викторович - канд. мед. наук, доцент кафедры хирургических болезней № 1, КГМУ, г. Курск. ORCID iD: 0000-0001-7578-6835. E-mail: tsandrej@yandex.ru

Тарабрин Денис Владимирович - канд. мед. наук, ассистент кафедры хирургических болезней № 1, КГМУ, г. Курск. ORCID iD: 0000-0002-5495-3611. E-mail: tarabrin.dv@ya.ru (автор, ответственный за переписку)

Кулабухов Алексей Сергеевич - канд. мед. наук, доцент, зав. кафедрой сестринского дела, КГМУ, г. Курск. E-mail: hernia2009@mail.ru

Тарабрина Ольга Владимировна - ассистент кафедры клинической иммунологии, аллергологии и фтизиопульмонологии, КГМУ, г. Курск. ORCID iD: 0000-0002-8462-4157. E-mail: tarabrinaksmu@mail.ru
\end{abstract}

Приоритетным направлением современной герниологии является улучшение результатов лечения больных с вентральными грыжами. Результаты лечения вентральных грыж, несмотря на широкое внедрение в клиническую практику новых хирургических материалов и технологий, нельзя считать удовлетворительными. Частота рецидивов грыж колеблется от $20 \%$ до $46 \%$ [2, 8, 11]. Наиболее частыми причинами рецидива грыж являются нарушения синтеза коллагена, а также выраженные дистрофические и воспалительные изменения в области грыжевых ворот, которые ведут к формированию некорректного рубца и компрометируют стандартно выполненную герниоимплантацию $[1,4,5,10]$. Сам процесс репаративной регенерации соединительной ткани в зоне герниоимплантации, а тем более в условиях предсуществующих воспалительных и/или дистрофических изменений, обязательно сопровождается реорганизацией волокнистого каркаса соединительнотканных структур. В свою очередь это меняет соотношение коллагеновых волокон разных калибров, механические свойства коллагеновых фибрилл, что в конечном итоге существенно тормозит процесс формирования соединительнотканной капсулы вокруг импланта [3, 7, 13, 14]. Одной из возможных причин нарушения образования коллагена в перипротезной капсуле также может являться врожденная или приобретенная 
энзимопатия. В этом случае количественный дефицит, или функциональная недостаточность коферментов аскорбиновой и оротовой кислоты, участвующих в гидроксилировании пролина и лизина, приводят к снижению выработки клетками-механоцитами молекул тропоколлагена субъединиц коллагеновых микрофибрилл. А это в свою очередь является причиной уменьшения количества коллагеновых микрофибрилл, формируемых в межклеточном пространстве посредством самосборки и, как следствие, приводит к уменьшению относительной плотности волокнистого каркаса ткани $[3,6,9,14]$. Такой механизм развития осложнений герниопластики базируется на том, что аскорбиновая кислота выполняет роль восстанавливающего агента для сохранения атома железа в ферроформе при гидроксилировании пролина и лизина, и при ее алиментарном гиповитаминозе развивается дефицит оксипролина, что и делает невозможным/затрудненным синтез полипептидных цепей - предшественников молекулы проколлагена. Недостаток оротовой кислоты оказывает негативное влияние на другом уровне организации коллагеновых волокон - нарушению образования поперечных сшивок и водородных связей. Это приводит к снижению прочности и упругости коллагеновых волокон, «разволокнению» толстых коллагеновых волокон [10, 12].

Цель работы - сравнительное экспериментальное изучение влияния препаратов витамина С и оротата калия на процесс формирования соединительнотканной капсулы вокруг сетчатого имплантата.

\section{МАТЕРИАЛЫ И МЕТОДЫ ИССЛЕДОВАНИЯ}

Эксперимент был выполнен на 150 белых сингенных лабораторных мышах-самцах со средним весом 25-35 гр. Лабораторные мыши проходили карантин в виварии ФГБОУ ВО Курского государственного медицинского университета Минздрава России.

Эксперименты выполнялись в строгом соответствии с Конвенцией Совета Европы от 1986 г. (Страсбург), а также директивой Совета 86/609/EЕС от 24.11.86. по согласованию законов, правил и административных распоряжений стран-участниц в отношении защиты животных, применяемых в экспериментальных исследованиях.

Были сформированы 3 группы наблюдения по 50 животных в каждой. Всем животным имплантировали бикомпонентный полурассасывающийся сетчатый герниоимплантат, состоящий из нерассасывающегося монофиламентного полипропилена и рассасывающейся монофи- ламентной полимолочной кислоты, с размером пор 1,6х1,0 мм.

I группе животных имплантировался герниоимплантат и животные получали стандартный пищевой рацион без добавления препаратов.

II группе животных имплантировался герниоимплантат и к стандартному пищевому рациону добавляли витамин С в виде раствора аскорбиновой кислоты из расчета 0,3 мг на 1 гр массы тела животного.

III группе животных имплантировался герниоимплантат и к стандартному пищевому рациону добавляли оротат калия в виде порошка из расчета 0,02 мг на 1 гр массы тела животного.

Оперативные вмешательства выполняли в асептических условиях операционной для мелких лабораторных животных НИИ ЭМ ФГБОУ ВО КГМУ Минздрава России. Под эфирным наркозом проводили депиляцию передней брюшной стенки с обработкой кожи $1 \%$ раствором йодопирона. Затем выполнялся разрез кожи на передней брюшной стенке длиной 1 см, и между апоневрозом и кожей формировали пространство, в которое помещали сетчатый имплантат размером 0,5х1,0 см без последующей его фиксации. Операционную рану ушивали непрерывным швом. Животных выводили из эксперимента на 7-е, 10-е, 30-е, 60-е, 90-е сутки путем декапитации под эфирным наркозом. Иссекали участок передней брюшной стенки размером 1,5х2 см вместе с имплантатом, который фиксировали в 10\% растворе нейтрального формалина. После автоматизированных стандартных процедур процессинга и микротомирования срезы толщиной 7-10 мкм окрашивали гематоксилином и эозином [4]. Микроскопию и микрофотографирование проводили с использованием системы Altami Polar 2 в проходящем свете при увеличениях х100, х250, х400. В параимплантатной капсуле на основании кариологических отличий дифференцировали клетки фибробластического ряда (от юных фибробластов до фиброцитов), макрофаги, лимфоциты и нейтрофилы. Подсчет этих видов клеток проводили в 10-ти неперекрещивающихся полях зрения [1]. Для определения стадии асептического воспаления и сравнительной оценки темпов пролиферации клеток фибробластического дифферона (регенерации соединительной ткани) вычисляли значение клеточного индекса для оценки регенераторного и воспалительного процесса. Статистический анализ полученных данных выполняли с применением программы Microsoft Excel-2010. Определяли описательные статистические показатели (среднее арифметическое, стандартное отклонение, ошибка средней, мода, медиана) и на их основе - тип распределения данных. При отсутствии нормаль- 
ного распределения данных для подтверждения статистической гипотезы (статистически значимого отличия сравниваемых групп при $\mathrm{p} \leq 0,05)$ вычисляли значение доверительного интервала [6].

\section{РЕЗУЛЬТАТЫ ИССЛЕДОВАНИЯ И ИХ ОБСУЖДЕНИЕ}

Сравнение клеточного состава регенерирующей вокруг герниоимплантата соединительной ткани в исследуемых группах животных показало, что в обеих экспериментальных группах уже на 7-е сутки после имплантации имплантата клетки фибробластического ряда количественно преобладают над клеткаминерезидентами. Но это отличие статистически значимо только во второй группе исследования (рис. 1). В ходе смены фаз воспаления с экссудативной на пролиферативную и на более поздних сроках наблюдения (10-е и 30-е сутки) такая тенденция сохраняется на фоне непрерывного возрастания относительной доли представителей фибробластического дифферона среди клеток капсулы. Некоторое превышение процента фибробластов над остальными клетками капсулы по сравнению с контрольной группой статистически недостоверно. И лишь на 60-е и 90-е сутки наблюдения такое превышение в группе III становится статистически значимым при $\mathrm{p} \leq 0,05$. Таким образом, анализ динамики количества клеток, участвующих в синтезе коллагеновых волокон показал, что в раннем послеопе- рационном

периоде

(7-30-е сутки) введение в пищевой рацион животных витамина С способствует более быстрому увеличению популяции фибробластов. Аналогичный эффект оротата калия реализуется позже, уже на стадии моделирования и ремоделирования капсулы вокруг нитей имплантата, на сроках 60 и 90 суток после экспериментального оперативного вмешательства.

Анализ динамики количественного представления нерезидентных клеток соединительной ткани в клеточном слое капсулы вокруг нитей имплантата показал, что на сроках наблюдения 7-е, 10-е и 90-е сутки в обеих экспериментальных группах (II и III) относительное количество макрофагов существенно и статистически достоверно превышает аналогичный показатель контрольной группы (рис. 2). Наиболее интересным представляется то, что на 30-е сутки наблюдения во II группе относительное количество макрофагов практически равно контрольной группе, а на 60-е сутки этот показатель выравнивается во всех трех группах экспериментальных животных. Принимая во внимание давно установленный факт участия макрофагов в процессах ремоделирования соединительной ткани посредством секреции ими нейтральных протеаз (коллагеназа и эластаза) [3, 14], следует полагать, что именно на этих сроках (30-е и 60-е сутки) в обеих экспериментальных группах происходит переключение фазы моделирования капсулы на фазу ее ремоделирования, что подтверждается относительным увеличением

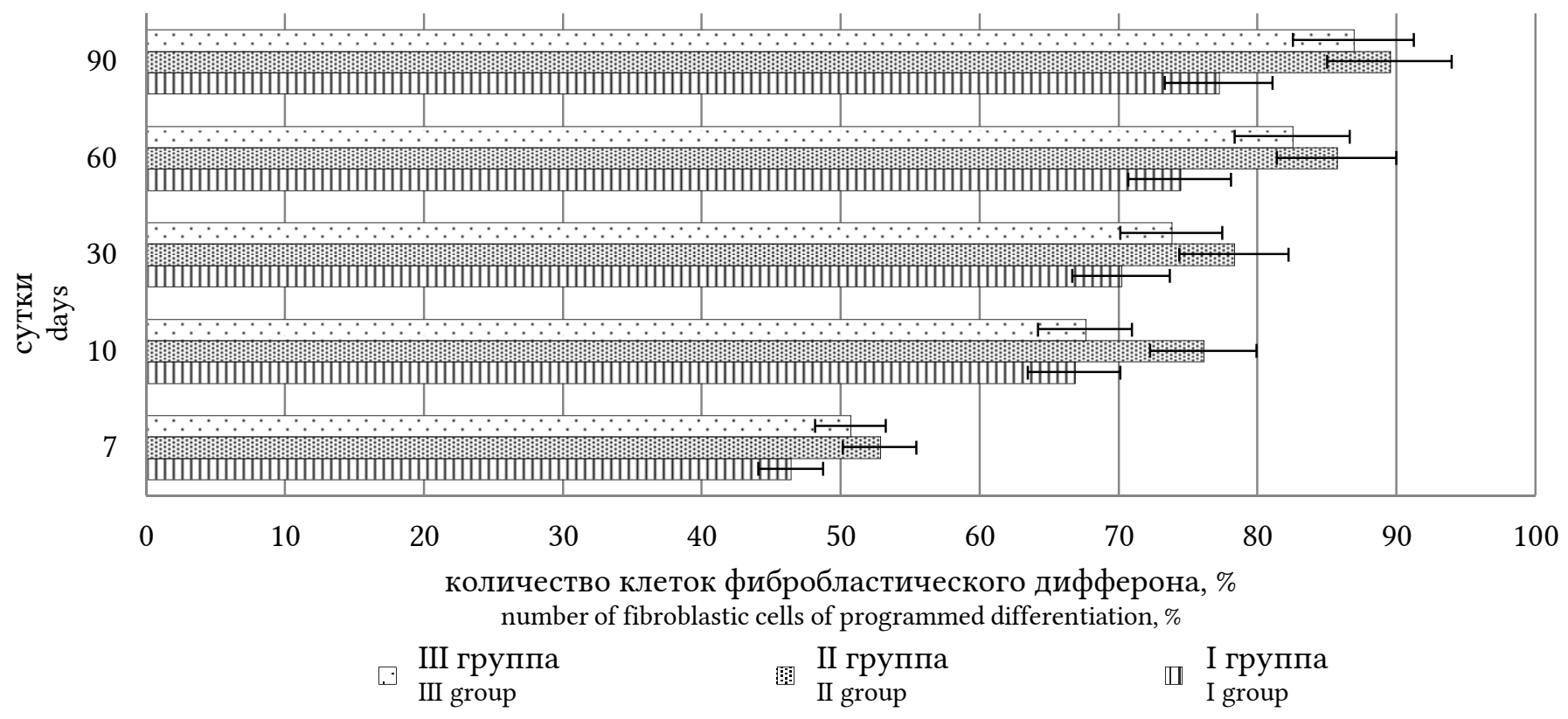

Рис. 1. Гистограмма относительного количества клеток фибробластического дифферона (в \%) в клеточном слое капсулы вокруг нитей имплантата в исследуемых группах.

Fig. 1. Histogram of the relative number of fibroblastic cells of programmed differentiation (\%) in the cell layer of the capsule around the implant threads in the studied groups. 


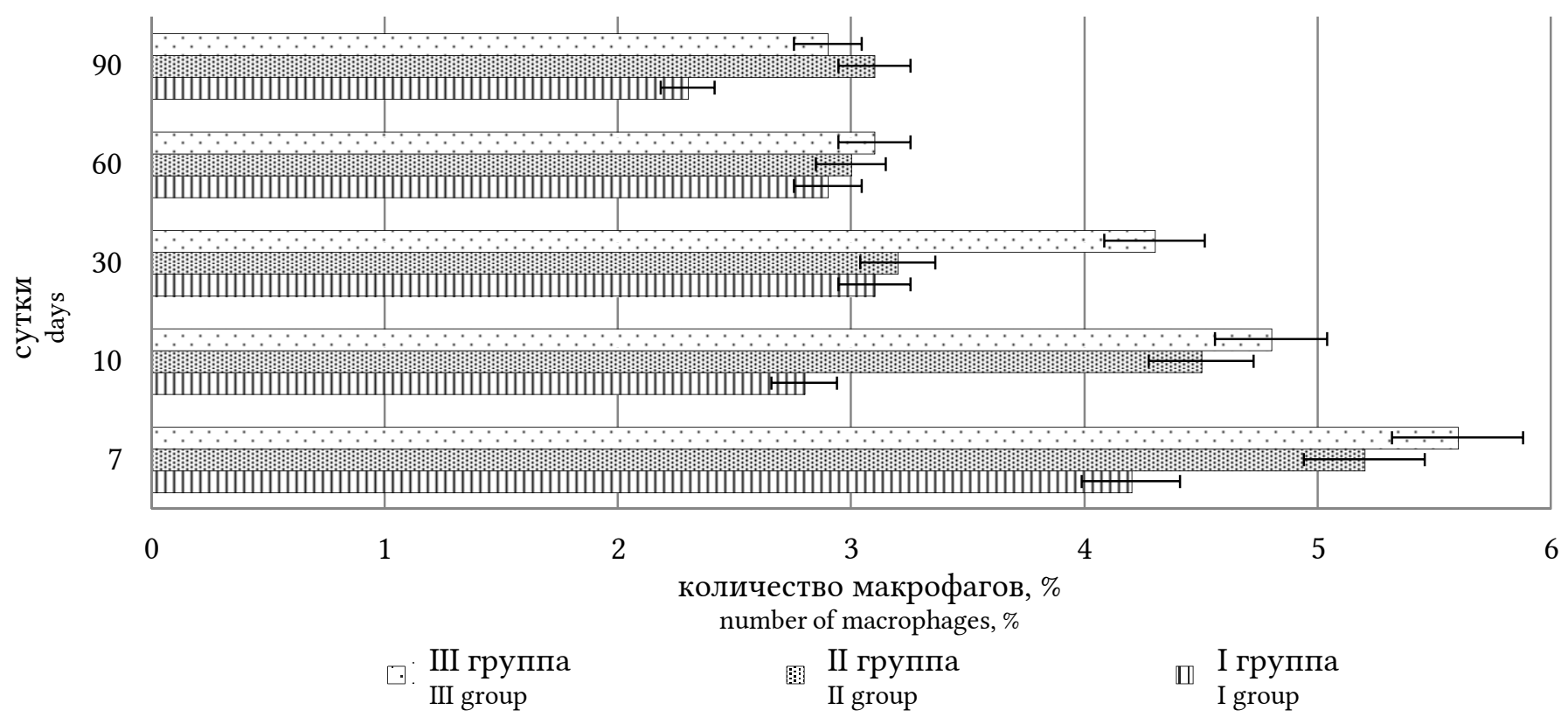

Рис. 2. Гистограмма относительного количества макрофагов (в \%) в клеточном слое капсулы вокруг нитей имплантата в исследуемых группах.

Fig. 2. Histogram of the relative number of macrophages (\%) in the cell layer of the capsule around the implant threads in the studied groups.

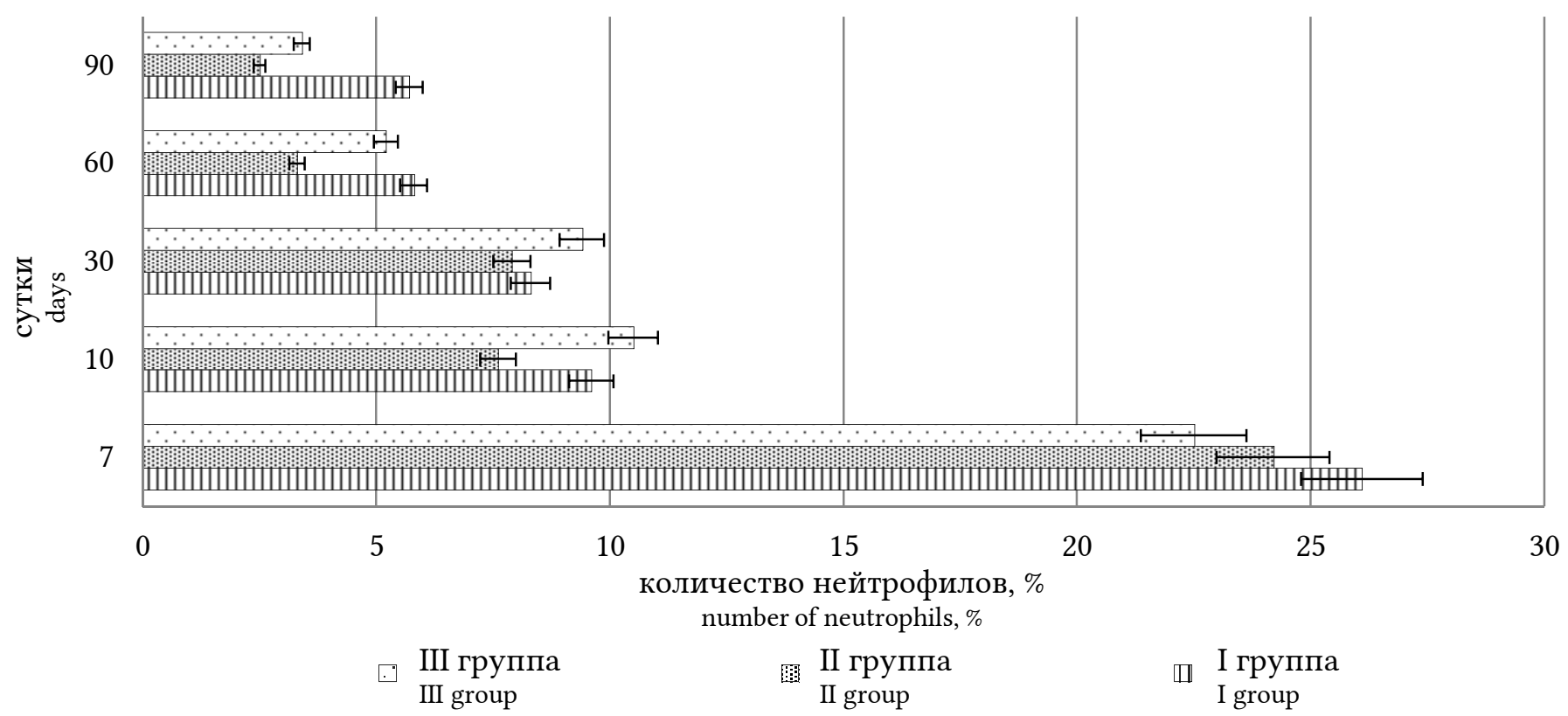

Рис. 3. Гистограмма относительного количества нейтрофилов (в \%) в клеточном слое капсулы вокруг нитей имплантата в исследуемых группах. groups.

Fig. 3. Histogram of the relative number of neutrophils (\%) in the cell layer of the capsule around the implant threads in the studied

количества макрофагов на 90-е сутки (рис. 2). Ремоделирование невозможно без разрушения предсуществующего волокнистого каркаса капсулы вокруг нитей имплантата. А самым мощным источником нейтральных протеаз в условиях асептического воспаления и без экссудации в зону воспаления нейтрофилов могут быть только макрофаги. Сравнение динамики их ко- личества в экспериментальных группах показывает, что в группе с применением витамина С это переключение происходит более плавно и за больший промежуток времени.

Исследование клеточного состава формирующейся капсулы вокруг нитей имплантата показало, что на протяжении всех сроков исследования наблюдается поступательное уменьшение 


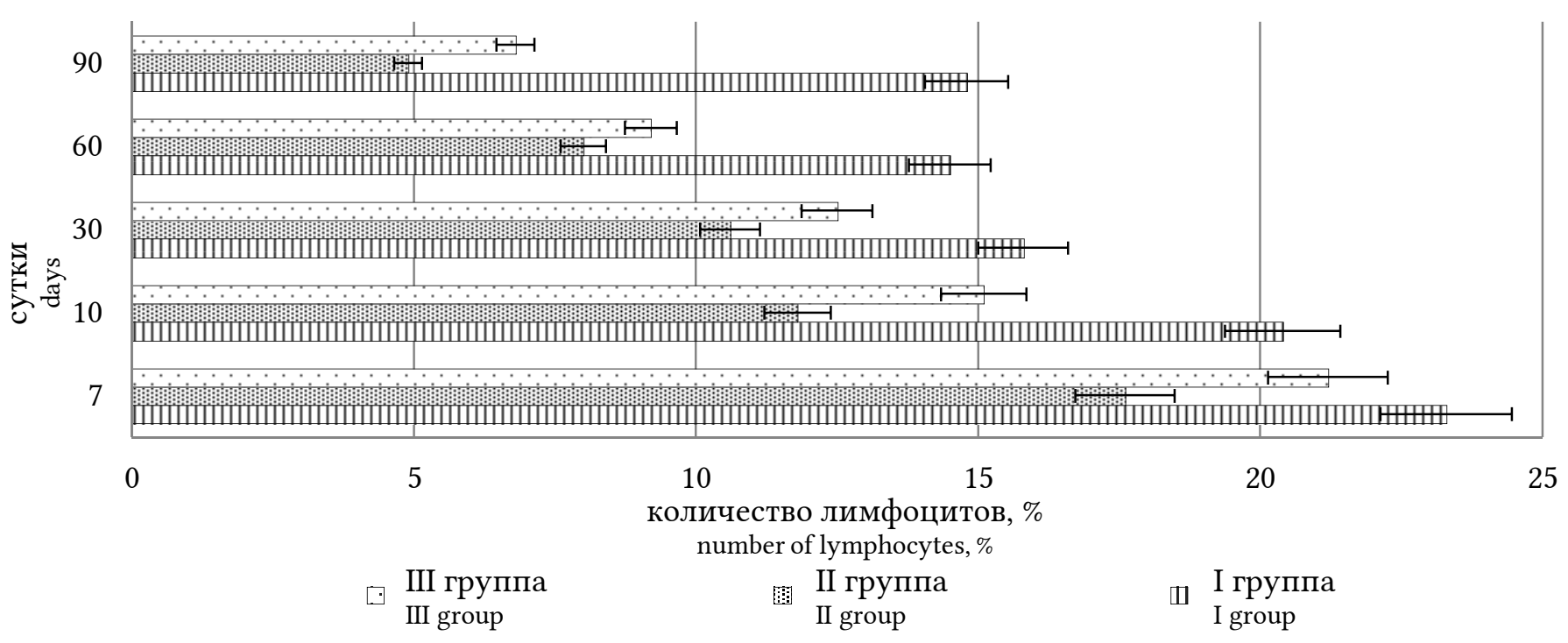

Рис. 4. Гистограмма относительного количества лимфоцитов (в \%) в клеточном слое капсулы вокруг нитей имплантата в исследуемых группах.

Fig. 4. Histogram of the relative number of lymphocytes (\%) in the cell layer of the capsule around the implant threads in the studied groups.

относительного содержания лимфоцитов и нейтрофилов в клеточном слое капсулы, которое более выражено в группах II и III по сравнению с контрольной группой. Уже на 7-е сутки в группе III отмечалось статистически достоверное уменьшение содержания нейтрофилов (рис. 3). Начиная с 10 суток наблюдения динамика этого процесса изменилась. «Лидером» в плане наименьшей экссудации нейтрофилов становится группа II, причем только на 30-е сутки это уменьшение статистически незначимо, в то время как на 10-е, 60-е и 90 -е сутки - это статистически достоверно. Практически такая же динамика установлена у лимфоцитов в клеточном слое капсулы вокруг нитей имплантата (рис. 4). В отличие от нейтрофильных гранулоцитов статистически значимые отличия отмечаются на всех сроках наблюдения как по сравнению экспериментальных групп с контрольной, так и между экспериментальными группами. Быстрее всего снижается относительное содержание лимфоцитов в капсуле вокруг нитей имплантата в группе с использованием аскорбиновой кислоты.

Сравнение относительного количества клеток разных типов (резидентов и нерезидентов) в клеточном слое капсулы вокруг нитей имплантата на сроках от 7-х до 90-х суток наблюдения позволяет сделать заключение, что введение в пищевой рацион животных оротата калия и аскорбиновой кислоты влияет на выраженность и продолжительность экссудативной фазы воспалительной реакции, снижая степень экссудации и ускоряя смену фазы экссудации фазой пролиферации.
Таким образом, возрастание относительного содержания фибробластов свидетельствует о том, что в обеих экспериментальных группах в клеточном слое капсулы складываются более комфортные условия для реализации синтетической функции фибробластов как в части синтеза аморфного межклеточного вещества, так и в части синтеза коллагена. Это подтверждалось не только достоверно более выраженной пролиферацией и созреванием клеток фибробластического ряда, но и формированием вокруг волокон имплантата прочного соединительнотканного каркаса. Особо следует отметить динамику относительного содержания макрофагов в экспериментальных группах II и III на поздних сроках наблюдения (60-е и 90-е сутки), которая, по нашему мнению, свидетельствует о начале фазы ремоделирования капсулы вокруг нитей имплантата.

Учитывая результаты использования препаратов, полученные в ходе эксперимента, можно говорить о необходимости изучения клинических результатов применения стимуляторов коллагеногенеза у пациентов с вентральными грыжами.

\section{КОНФЛИКТ ИНТЕРЕСОВ}

Авторы декларируют отсутствие явных и потенциальных конфликтов интересов, связанных с публикацией настоящей статьи.

\section{ИСТОЧНИКИ ФИНАНСИРОВАНИЯ}

Авторы заявляют об отсутствии финансирования. 


\section{СООТВЕТСТВИЕ ПРИНЦИПАМ ЭТИКИ}

Протокол исследования одобрен региональным этическим комитетом Курского государственного медицинского университета, протокол № 1 от 26.01.2015 г

\section{ЛИЧНЫЙ ВКЛАД АВТОРОВ}

В.А. Лазаренко - разработка концепции и дизайна, окончательное утверждение для публикации рукописи; И.С. Иванов - определение стратегии исследования, разработка концепции и дизайна исследования, окончательное утверждение для публикации рукописи; С.В. Иванов - определение стратегии исследования, разработка концепции и дизайна исследования, анализ полученных данных, редактирование; А.В. Иванов - анализ полученных данных, редактирование; Д.В. Тарабрин - анализ полученных данных, редактирование, подготовка текста, проверка критически важного интеллектуального содержания; А.В. Цуканов - анализ полученных данных, статистическая обработка; А.С. Кулабухов - анализ и интерпретация данных; О.В. Тарабрина - анализ и интерпретация данных, статистическая обработка.

\section{ЛИТЕРАTУРA/REFERENCES}

1. Автандилов Г.Г. Медицинская морфометрия: руководство. Москва: Медицина, 1990. 384 с. [Avtandilov G.G. Medical morphometry: a guide. Moscow: Meditsina, 1990. 384 p. (in Russ.)]

2. Иванов С.В., Лазаренко В.А., Иванов И.С., Иванов А.В., Цуканов А.В., Розберг Е.П., Попова Л.П., Тарабрин Д.В., Объедков Е.Г. Морфологические особенности парапротезной капсулы при имплантации полипропиленового и композиционного эндопротезов на фоне применения оротовой кислоты в эксперименте. Новости хирургии. 2016; 24(5): 436-442 [Ivanov S.V., Lazarenko V.A., Ivanov I.S., Ivanov A.V., Tsukanov A.V., Rozberg Y.P., Popova L.P., Tarabrin D.V., Obyedkov Y.G. Morphological features of paraprosthesis capsules in implantation of polypropylene and composite endoprosthesis against application of orotic acid in the experiment. Novosti khirurgii. 2016; 24(5): 436-442 (in Russ.)]

3. Кочетов А.Г., Лянг О.В., Масенко В.П., Жиров И.В., Наконечников С.Н., Терещенко С.Н. Методы статистической обработки медицинских данных : метод. рекомендации для ординаторов и аспирантов мед. учеб. заведений, науч. работников. Москва: РКНПК, 2012. 42 с. [Kochetov A.G., Lyang O.V., Masenko V.P., Zhirov I.V., Nakonechnikov S.N., Tereshchenko S.N. Methods of statistical processing of medical data: guidelines for residents and graduate students of medical schools, researchers. Moscow: RKNPK, 2012. 42 p. (in Russ.)]

4. Лилли Р., под ред. Португалова В.В. Патогистологическая техника и практическая гистохимия. Москва: Мир, 1969. 646 с. [Lilli R., Portugalov V.V., editor. Histopathological technique and practical histochemistry. Moscow: Mir, 1969. 646 p. (in Russ.)]

5. Маянский А.Н. Очерки о нейтрофиле и макрофаге. Новосибирск: Наука, 1983. 256 с. [Mayanskiy A.N. Essays on the neutrophil and macrophage. Novosibirsk: Nauka, 1983. 256 p. (in Russ.)]

6. Пономарева Ю.В., Белоконев В.И., Волова Л.Т., Гуляев М.Г. Морфологические основы причин рецидивов у больных с послеоперационной вентральной грыжей. Фундаментальные исследования. 2013; 9-2: 263-266 [Ponomareva Y.V., Belokonev V.I., Volova L.T., Gulyaev M.G. The morphological basis of the causes of recurrence in patients with postoperative ventral hernias. Fundamental'nyye issledovaniya. 2013; 9-2: 263-266 (in Russ.)]

7. Рыбачков В.В., Садижов Н.М., Шубин Л.Б., Соколов С.В., Кабанов Е.Н., Быков А.С. Структурнофункциональная оценка нарушений синтеза коллагена в тканях передней брюшной стенки в эксперименте. Вестник Ивановской медицинской академии. 2016;21(2): 65-66 [Rybachkov V.V., Sadizhov N.M., Shubin L.B., Sokolov S.V., Kabanov E.N., Bykov A.S. Structural functional evaluation of collagen synthesis disorders in anterior abdominal wall tissues in experiment. Vestnik Ivanovskoy meditsinskoy akademii. 2016; 21(2): 65-66 (in Russ.)]

8. Самарцев В.А., Гаврилов В.А., Паршаков А.А., Кузнецова М.В. Задняя сепарационная герниопластика TAR при послеоперационных вентральных грыжах W3. Пермский медицинский журнал. 2017; 34(1): 35-42 [Samartsev V.A., Gavrilov V.A., Parshakov A.A., Kuznetsova M.V. Posterior separation hernioplasty tar in treatment of postoperative ventral hernias W3. Perm Medical fournal. 2017; 34(1): 35-42 (in Russ.)]

9. Ступин В.А., Джафаров Э.Т., Черняков А.В., Кротт Э., Клинге У., Ануров М.В., Поливода М.Д., Титкова С.М., Эттингер А.П. Особенности соединительной ткани у пациентов с послеоперационными вентральными грыжами. Вестник Российского государственного медицинского универсиmema. 2009; 5: 7-10 [Stupin V.A., Dzhafarov E.T., Chernyakov A.V., Krott E., Klinge U., Anurov M.V., Polivoda M.D., Titkova S.M., Oettinger A.P. Special features of connective tissue in patients with incisional ventral hernias. Bulletin of Russian State Medical University. 2009; 5: 7-10 (in Russ.)]

10. Franzke C.W., Bruckner P., Bruckner-Tuderman L. Collagenous transmembrane proteins: recent insights into biology and pathology. F Biol Chem. 2005; 280(6): 4005-4008. DOI: 10.1074/jbc.R400034200

11. Heybeli T., Kulacoglu H., Genc V., Ergul Z., Ensari C., Kiziltay A., Yilmazer D., Serbetci K., Hasirci N. Basic fibroblast growth factor loaded polypropylene meshes in repair of abdominal wall defects in rats. Chirurgia (Bucur). 2010; 105(6): 809-816.

12. Jenney C.R., DeFife K.M., Cotton E., Anderson J.M. Humanmonocyte/macrophage adhesion, macrophage motility, and IL-4-induced foreign body giant cell formation on silane-modified surface in vitro. 7 Biomed Mater Res. 1998; 41(2): 171-184. 
13. Meintjes J., Yan S., Zhou L., Zheng S., Zheng M. Synthetic, biological and composite scaffolds for abdominal wall reconstruction. Expert Rev Med Devices. 2011; 8(2): 275-288. DOI: 10.1586/erd.10.64.
14. Telang P.S. Vitamin C in dermatology. Indian Dermatol Online f. 2013; 4(2): 143-146. DOI: $10.4103 / 2229$ 5178.110593 .

Для цитирования: Лазаренко В.А., Иванов С.В., Иванов И.С., Иванов А.В., Цуканов А.В., Тарабрин Д.В., Кулабухов А.С., Тарабрина О.В. Сравнительный анализ влияния витамина С и оротата калия на морфологическую картину при имплантации герниоимплантата в эксперименте. Курский научно-практический вестник «Человек и его здоровье». 2019;(1):33-40. DOI: $10.21626 /$ vestnik/2019-1/04.

\title{
COMPARATIVE ANALYSIS OF THE EFFECT OF VITAMIN C AND POTASSIUM OROTATE ON THE MORPHOLOGICAL PICTURE DURING THE IMPLANTATION OF A HERNIA MESH IN AN EXPERIMENT
}

\author{
(c) Lazarenko V.A., Ivanov S.V., Ivanov I.S., Ivanov A.V., Tsukanov A.V., \\ Tarabrin D.V., Kulabukhov A.S., Tarabrina O.V.
}

Kursk State Medical University (KSMU)

3, K. Marx st., Kursk, Kursk region, 305041, Russian Federation

\begin{abstract}
Objective. The aim of the research was a comparative experimental study of the effect of vitamin C and potassium orotate preparations on the formation of a connective tissue capsule around a mesh implant.

Materials and methods. The experiment was performed on 150 white mice. The first group of animals received a standard diet after surgery. The diet of second and third animal groups was supplemented with vitamin $\mathrm{C}$ and potassium orotate, respectively. Histological sections obtained from the animals were placed on glass slides and stained with hematoxylin and eosin. The morphometry was performed afterwards in the capsule around the implant threads.

Results. Being compared the cellular composition of the connective tissue regenerating around the hernia implant in the studied groups of animals showed that in both experimental groups, on the 7th day after implantation, fibroblastic cells predominated over non-resident cells. In the early postoperative period (7-30 days), the introduction of vitamin $\mathrm{C}$ into the diet contributed to a more rapid increase in the fibroblast population. A similar effect of potassium orotate is realized later, already at the stage of modeling and remodeling the capsule around the implant threads, on 60 and 90 days after the experimental surgical intervention.
\end{abstract}

Conclusion. In the experiment, the effect of drugs in the zone of implantation of a hernioimplant was determined, which was manifested itself by a significantly more pronounced proliferation of fibroblast cells.

Keywords: ventral hernia; collagen; morphometry.

Lazarenko Viktor A. - DM, Professor, Rector, Head of Surgical Diseases Department of FPE, KSMU, Kursk, Russian Federation. ORCID iD: 0000-0002-2069-7701. E-mail: azaroks@mail.ru

Ivanov Sergey V. - DM, Professor, Head of Surgical Diseases No 1 Department, KSMU, Kursk, Russian Federation. ORCID iD: 00000001-7540-5748. E-mail: gospithirivanov@yandex.ru

Ivanov Il'ya S. - DM, Professor, Professor of Surgical Diseases No 1 Department, KSMU, Kursk, Russian Federation. ORCID iD: 0000-0003-4408-961X. E-mail: ivanov.is@mail.ru

Ivanov Aleksandr V. - DM, Professor, Head of Histology, Embryology, Cytology Department, KSMU, Kursk, Russian Federation. ORCID iD: 0000-0002-2412-0475. E-mail: anatomy@mail.ru

Tsukanov Andrey V. - PhD in Medicine, Associate Professor of Surgical Diseases No 1 Department, KSMU, Kursk, Russian Federation. ORCID iD: 0000-0001-7578-6835. E-mail: tsandrej@yandex.ru

Tarabrin Denis V. - PhD in Medicine, Assistant of Surgical Diseases No 1 Department, KSMU, Kursk, Russian Federation. ORCID iD: 0000-0002-5495-3611. E-mail: tarabrin.dv@ya.ru (correspondence author)

Kulabukhov Aleksey S. - PhD in Medicine, Associate Professor, Head of Nursing Care Department, KSMU, Kursk, Russian Federation. E-mail: hernia2009@mail.ru

Tarabrina Ol'ga V. - Assistant of Clinical Immunology, Allergology and Phthisiopulmonology Department, KSMU, Kursk, Russian Federation. ORCID iD: 0000-0002-8462-4157. E-mail: tarabrinaksmu@mail.ru

\section{CONFLICT OF INTEREST}

The authors declare the absence of obvious and potential conflicts of interest related to the publication of this article.

\section{SOURCE OF FINANCING}

The authors state that there is no funding for the study.

\section{CONFORMITY WITH THE PRINCIPLES OF ETHICS}

The Study protocol was approved by the Regional Ethical Committee under Kursk State Medical University (Protocol No. 1 of 26.01.2015). 


\section{AUTHORS CONTRIBUTION}

Lazarenko V.A. - developing the research concept and design, final approval of the manuscript for publication; Ivanov S.V. - determining the research strategy, developing the research concept and design; final approval of the manuscript for publication; Ivanov I.S. - determining the research strategy, developing the research concept and design, data analyzing, editing; Ivanov A.V. - data analyzing, editing; Tarabrin D. V. data analyzing, editing, text preparation, critical revision of the manuscript for important intellectual content; Tsukanov A. V. data analyzing, statistical data analysis; Kulabukhov A.S. - data analyzing and interpreting the results; Tarabrina O.V. - data analyzing and interpreting the results, statistical data analysis.

Received 23.10.2018

Accepted 21.03.2019

For citation: Lazarenko V.A., Ivanov S.V., Ivanov I.S., Ivanov A.V., Tsukanov A.V., Tarabrin D.V., Kulabukhov A.S., Tarabrina O.V. Comparative analysis of the effect of vitamin $\mathrm{C}$ and potassium orotate on the morphological picture during the implantation of a hernia mesh in an experiment. Kurskiy nauchno-prakticheskiy vestnik "Chelovek i ego zdorov'ye" = Kursk Scientific and Practical Bulletin "Man and His Health”. 2019;(1):33-40. DOI: 10.21626/vestnik/2019-1/04. 